\title{
Accelerated failure time modelling of Tuberculosis predictors in HIV/AIDS patients in Albert Luthuli Municipality of South Africa
}

Pepukai Bengura ( $\nabla$ 31659322@mylife.unisa.ac.za )

University of South Africa

Principal Ndlovu

University of South Africa

Mulalo Annah Managa

University of South Africa

\section{Research Article}

Keywords: HIV/AIDS, Tuberculosis, ART, predictors, Survival analysis, AFT model, Kaplan-Meier, log-rank, hazard ratios.

Posted Date: September 9th, 2020

DOl: https://doi.org/10.21203/rs.3.rs-71793/v1

License: (c) (i) This work is licensed under a Creative Commons Attribution 4.0 International License. Read Full License 


\title{
Accelerated failure time modelling of Tuberculosis predictors in HIV/AIDS patients in Albert Luthuli Municipality of South Africa
}

\author{
Pepukai Bengura $^{1 *}$, Principal Ndlovu ${ }^{2}$ and Mulalo Annah Managa ${ }^{2}$
}

\begin{abstract}
Background: Tuberculosis (TB) is one of the most common opportunistic diseases and leading cause of death among Human immunodeficiency virus and acquired immune deficiency syndrome (HIV/AIDS) patients. There has been a drastic rise of TB infection associated with the pandemic occurrence of HIV/AIDS infection in South Africa and other resource-limited countries world-wide. South Africa faces an immense burden on health care systems posed by diagnostic and therapeutic challenges resulting from the concomitant HIV and TB epidemics. This study aimed to determine the prevalence and the factors associated with TB and HIV coinfection for patients attending clinical care at rural public health facilities in Albert Luthuli municipality of South Africa.
\end{abstract}

Methods: A cohort of HIV/AIDS patients was retrospectively followed from inception in 2010 to 2017 until TB was diagnosed or until the end of the study. Accelerated Failure Time (AFT) model was used to analyse survival data on HIV/AIDS patients. Factors associated to TB were modelled using log-logistic AFT model and further analysis of the significant factors was done using Kaplan-Meier, log-rank and hazard ratios.

Results: From 357 HIV/AIDS patients, 65 patients (18.2\%) had TB. Out of the 65 HIV/AIDS patients with TB, 15 (23.1\%) of them died. Thus, of the 41 HIV/AIDS patients who died during the follow-up period, 15 of them $(36.6 \%)$ had TB. Log-logistic AFT model determined factors associated with TB at significance level of 0.05 as: hospital, WHO stage, treatment (regimen 1), ART adherence, follow-up CD4 count, baseline haemoglobin, follow-up white blood cell count, baseline viral load, baseline sodium and follow-up alanine transaminase.

Discussion: Although antiretroviral therapy is effective in reducing the risk of developing TB, the overall burden of TB in HIV/AIDS community may not substantially diminish.

Conclusion: TB/HIV co-infection is one of the serious public health problems in Albert Luthuli municipality. Collaborative TB/HIV activities in form of early diagnosis of both TB and HIV need a holistic approach in order to reduce drug resistance, drug toxicity, comorbidities and mortalities which are associated with TB/HIV co-infection.

Keywords: HIV/AIDS, Tuberculosis, ART, predictors, Survival analysis, AFT model, Kaplan-Meier, log-rank, hazard ratios. 


\section{Introduction}

Tuberculosis is the leading cause of death in South Africa (South Africa National AIDS Council, 2017). The country has the world's sixth largest tuberculosis (TB) epidemic, with a TB incidence rate of 438,000 in 2016 (South Africa National AIDS Council, 2017). The HIV epidemic in South Africa fuels the TB epidemic because people living with HIV are at a far higher risk of developing TB due to weakened immune systems. It is estimated that $60 \%$ of people living with HIV in South Africa are also co-infected with TB. In 2016 there were 73,000 HIV/TB deaths (South Africa National AIDS Council, 2017).

According to the World Health Organization (WHO)(2018), around one-third of the 36.9 million people living with HIV and AIDS worldwide are co-infected with TB. Sub-Saharan Africa is the hardest hit region, as it has about 70\% of all people living with HIV/AIDS and TB co-infection in the world (UNAIDS, 2018). Despite the successful scale-up of ART programmes in the Sub-Saharan Africa, opportunistic infections remain a frequent cause of morbidity, hospitalization and death. Progress on reducing TB-related deaths among people living with HIV is being made, as the number of deaths declined by 100,000 between 2015 and 2017, mainly due to the rapid expansion of antiretroviral HIV treatment (WHO, 2018). According to Diedrich and Flynn (2011), the emergence of human immunodeficiency virus type 1 (HIV) has exacerbated an already enormous number of cases of tuberculosis (TB) worldwide. Getahun et al. (2010) noted that TB affects HIV individuals throughout all phases of HIV infection and is the leading killer of HIV people.

The escalation of TB cases resulting from the improved survival among HIV patients and from the growing TB drug resistance and TB/HIV co-infection drug toxicity has resulted in South Africa bearing the most serious TB crisis in the world. South Africa is among the worst affected countries in the world by both HIV and TB infection. Despite having just $0.7 \%$ of the world's population in 2007, South Africa had 17\% of the global burden of HIV infection, and had one of the world's worst tuberculosis epidemics which was compounded by rising drug resistance and HIV co-infection (Karim et al., 2009). In 2017, Stop TB Partnership's Global Plan to End TB estimated the annual global funding for TB in low and middle income countries to be around US $\$ 10.4$ billion in 2018 and increasing to US $\$ 12.3$ billion in 2020 , while an additional US $\$ 2$ billion per year was needed for TB research and development. 
There are various determinant factors that increase the chance of $\mathrm{TB}$ infection among HIV/AIDS patients. Infection with HIV is the most powerful known risk factor predisposing for Mycobacterium tuberculosis infection and progression to active disease (Pawlowski et al., 2012 \& Alimuddin Zumla, 2000). The shared compromised immune defence mechanisms between HIV and TB makes HIV infection speeds up the progression from latent to active TB while TB bacteria accelerates the progress of HIV infection. Bruchfeld et al. (2015) found out that the two pathogens, Mycobacterium tuberculosis and HIV, potentiate each other, and hence accelerating the deterioration of immunological functions and resulting in premature death if untreated. The risk of developing active TB is estimated to be 20 times greater in people living with HIV than in people who are HIV-negative (WHO, 2018). In agreement with WHO, the findings by Luetkemeyer (2019) show that the risk of progressing from latent to active TB is estimated to be between 12 and 20 times greater in people living with HIV than among those without HIV infection. Clinical studies done by Glynn et al. (2008) provide compelling evidence that HIV leads to an increased risk of developing TB shortly after HIV infection. Current TBcontrol measures could be failing largely as a result of the human immunodeficiency virus (HIV) epidemic. Evaluation of additional control interventions requires detailed understanding of the epidemiological relationship between these diseases at the community level.

Data based evidence show that TB is worryingly prevalent in Albert Luthuli municipality. Consequently, the main objective of the study was to assess the impact of HIV/AIDS and TB coinfection on survival of patients after adjusting for potential explanatory variables. 


\section{Methods used}

\section{Data sources}

A cohort of HIV-infected patients from Embhuleni and Carolina district hospitals were retrospectively followed from 2010 to 2017 until TB was diagnosed or until the end of the study. Since the exact date of TB onset is not known, the event TB is known to lie in an interval that is the last available visit date and end of the study. Thus, the observed event leads to interval censored survival data. Albert Luthuli Local Municipality is a South African local municipality situated in the Gert Sibande District of Mpumalanga. Carolina and Embhuleni District hospitals, from where data was collected, render comprehensive health care service which includes HIV and TB treatments and support services to the surrounding communities in Albert Luthuli municipality. These hospitals are accredited antiretroviral (ARV) treatment initiation and on-going treatment sites. Both Hospitals serve mostly the rural population in Albert Luthuli Municipality. The target population which was used as a sampling frame included all HIV/AIDS patients admitted and started ART treatment in the two hospitals within the three-month period from the $1^{\text {st }}$ of January to the $31^{\text {st }}$ of March 2010. The variables which form part of the routine hospital records in Albert Luthuli municipality were used in this study and are described as follows. Being tuberculosis co-infected or not co-infected is the dependent variable for the study. It was recorded as TB history (yes, no). The categorical independent variables were gender, hospital (Carolina, Embhuleni), WHO stage (1, 2, 3, 4), marital status ( single, married, staying together, widowed/separated/divorced), treatments (regimen 1) $(\mathrm{NVP}+\mathrm{D} 4 \mathrm{~T}+3 \mathrm{TC}, \quad \mathrm{EFV}+\mathrm{D} 4 \mathrm{~T}+3 \mathrm{TC}, \quad \mathrm{EFV}+\mathrm{AZT}+3 \mathrm{TC}$ and $\mathrm{EFV}+3 \mathrm{TC}+\mathrm{TDF}), \quad \mathrm{ART}$ adherence (poor, fair, good), transferred from hospital (yes, no) and lost to follow-up (yes, no). The continuous independent variables for the study which except age were classified into baseline and follow-up variables were mass, CD4 cell count, haemoglobin, lymphocyte, white blood cell count, viral load, creatinine, total protein, sodium and alanine transaminase. Diabetes and hypertension were excluded because their records were found in very few patient files.

\section{Sample size and sampling procedure}

Sample size was determined by using sample size calculation formula for survival analysis by considering the following statistical assumptions on HIV-infected patients: an average of $24 \%$ prevalence rate of TB among HIV+ patients on ART (Mekonnen et al., 2015), 5\% precision or margin error, 95\% level of confidence interval and 0.20 loss in TB patients (Masini et al., 
2016). The sample size was calculated using the formula (Eneyew et al., 2016), $N=\frac{Z^{2} p(1-p)}{\alpha^{2}}$, where $\mathrm{N}=$ sample size, $\mathrm{Z}=1.96$ (critical value at $95 \%$ level of confidence), $\mathrm{p}=$ proportion of TB patients and $\alpha=$ type- 1 error (0.05) was 357 . The estimated total sample size was proportionally and randomly allocated to the two study sites (Embhuleni and Carolina hospitals with proportions of $79 \%$ and $21 \%$ respectively) and according to the age and gender proportions (39.4\% male) as per population proportions.

\section{TB diagnosis and treatment}

The clinical manifestations of TB vary but include prolonged fever, hemoptysis, productive cough, weight loss or night sweat to minimal or nonspecific symptoms. However, many people with both TB and HIV infection have few symptoms of TB and this makes it even more difficult to diagnose TB in HIV positive individuals than to diagnose TB in people without HIV infection. Subsequently, there can be delays in both TB diagnosis and TB treatment. Sputum microscopy and culture with drug-susceptibility testing are recommended as a standard method for diagnosing active TB. Currently, a two-month initial intensive phase of isoniazid, rifampin, pyrazinamide and ethambutol, followed by four months of continuation phase of isoniazid and rifampin is considered as the treatment of drug-susceptible TB (Manosuthi et al., 2016).

\section{Statistical analysis}

\section{Model Comparison}

In order to select best fit model, we have used -2 Log-likelihood, AIC, AICC and BIC. Loglogistic AFT model was adopted after comparison with Log-normal and Exponential by using AIC, BIC, AICC and Log-likelihood. The AIC guards against over fitting and it is defined as: $A I C=-2 * \log -$ likelihood $+2(p+k)$ where, $p$ is the number of covariates in the model, with $k=1$ for exponential and $k=2$ for Weibull, log-logistic and log-normal models. The AIC penalizes the number of parameters less strongly than the BIC (Schwarz, 1978). BIC is defined as: $B I C=-2 * \log -$ likelihood $+p \cdot \log (n)$, where, $p$ represents the number of covariates in the model and $\mathrm{n}$ represents the number data points. The model with the least value for each of the following: -2 Log-likelihood, AIC, AICC or BIC is regarded the best model.

\section{Accelerated Failure Time Model (AFTM)}

The hazard function, probability density function and survival function for a log-logistic model with parameters $\alpha, \lambda>0$ are respectively given by: $h(t)=\frac{\alpha t^{\alpha-1} \lambda}{1+\lambda t^{\alpha}}, f(t)=\frac{\alpha t^{\alpha-1} \lambda}{\left[1+\lambda t^{\alpha}\right]^{2}}$ and $S(t)=$ 
$\frac{1}{1+\lambda t^{\alpha}}$. Suppose that ' $\mathrm{n}$ ' is the number of HIV/AIDS patients who are under ART and let $T_{i}$ be the survival time (i.e., time to the onset of TB after ART initiation) of the $i^{\text {th }}$ HIV/AIDS patient with survival function $S(t)$. Let $\left(L_{i}, R_{i}\right)$ be the interval in which $T_{i}$ is being observed, such that $L_{i}<T_{i}<R_{i}$ where $L_{i}$ is the time period from the beginning of the follow-up until the diagnosis of TB. If the event does not occur till the end of the study, then the patient is said to be right censored $\left(R_{i}\right)$. Let $X=\left(X_{i 1}, X_{i 2}, \ldots X_{i p}\right)^{\prime}$ be the values of $\mathrm{p}$ covariates for the $i^{\text {th }}$ patient. Then the log linear form of AFT model describes a linear relationship between logarithm of the survival time and covariates, as given by Kim (1997) and as in Swain and Grover (2015):

$\log T_{i}=\beta_{1} x_{i 1}+\beta_{2} x_{i 2}+\cdots+\beta_{2} x_{i p}+\sigma \omega_{i}$

Or

$Y_{i}=\log \left(T_{i}\right)=\mu+X^{\prime} \beta+\sigma \omega$

where, $X^{\prime}$ is a vector of regression coefficients, $\mu$ and $\sigma$ are intercept and scale parameters respectively and the error term $\omega_{i}$. This transformation leads to the Weibull, log-normal or loglogistic AFT models for $T_{i}$ (Collett, 2003).

\section{Maximum Likelihood Estimation}

Given $Y_{i}=\log \left(T_{i}\right)$ as in 1.2 , then the density function of $Y_{i}$ is given by $\frac{f(w)}{\sigma}$, where $w=$ $\frac{\left(y-X^{\prime} \beta\right.}{\sigma}$. By assuming that $X_{i 1}=1$ for all $i$, then the likelihood function for the set of the observed intervals can be written as: $L(\beta, \sigma)=\prod_{i=1}^{n}\left[\frac{f\left(w_{L i}\right)}{\sigma}\right]^{\delta_{i}}\left[S\left(w_{L i}\right)-S\left(w_{R i}\right)\right]^{1-\delta_{i}}$

Where: $w_{L i}=\frac{\left(\log L i-X_{i}^{\prime} \beta\right)}{\sigma}, w_{R i}=\frac{\left(\log R i-X_{i}^{\prime} \beta\right)}{\sigma}, S(w)=\int_{w}^{\infty} f(s) d s$ and $\delta_{i}= \begin{cases}1 & \text { if } L_{i}=R_{i} \\ 0 & \text { otherwise }\end{cases}$ The functions $f(w)$ and $S(w)$ denote the probability density and survival functions of the error variable $\mathrm{w}$ in (1.2) respectively. The estimates can now be obtained by maximizing the likelihood equation (3) with respect to $\beta$ and $\sigma$ as in Klein and Moeschberger (2003).

\section{Modelling and analysis approaches}

Variables with p-values less than 0.05 were incorporated into the multivariate model. Let $t_{(1)}<$ $t_{(2)}<t_{(3)}<\cdots<t_{(n)}$ denote the ordered survival times, censored or not, with corresponding indicator $d_{(k)}$ for $t_{(k)}$. The Kaplan-Meier estimate for survival probability $S_{(j)}=\operatorname{Pr}\left\{X>t_{(j)}\right\}$ 
is then $\hat{S}_{(j)}=\prod_{k \leq j}\left(\frac{n-k}{n-k+1}\right)^{d_{(k)}}$. Log-rank test, Kaplan-Meier survivor functions and hazard ratios were used as analysis approaches in addressing homogeneity with respect to the characteristics of the cohort. Log-rank test was used to compare TB survival rates between two distinct groups using the hypothesis:

$H_{0}$ : All survival curves are the same versus $H_{1}$ : Not all survival curves are the same. Data were for the study were recorded on research tools and then captured on Microsoft excel database and checked against original records by two competent individuals. Data was analysed using SAS Version 9.4, Stata Version 15 and R Version 3.5.1.

\section{Inclusion and Exclusion Criteria}

This study considered all HIV/AIDS patients admitted and started ART treatment in the two hospitals within the three-month period from the $1^{\text {st }}$ of January to the $31^{\text {st }}$ of March 2010 . HIV/AIDS patients were excluded from the study if the patient medical register had missing essential records such as admission and last follow-up dates, TB history and date of birth or age.

\section{Ethical consideration}

The University of South Africa Ethics Review Committee and the Mpumalanga Department of Health approved the protocol for this study. All data related to the patient were handled with utmost confidentiality in all the stages of the research. In addition, no reference to an individual respondent was recorded and all results were handled in aggregate format. The electronic documents carrying confidential information on patients are all protected by some encryption and will be destroyed as per research policy. 


\section{Results}

\section{Descriptive statistics}

Descriptive statistics show that most TB cases from HIV-infected patients are from females (60\%), Embhuleni hospital (96.9\%), WHO stages 3 and 4 (89.2\%), poor and fair adherence (93.8\%) and treatment (regimen 1) ( EFV+D4T+3TC) (66.2\%). Most TB cases from HIVinfected patients are from the first year (44.6\%) and second year (36.9\%) of the period of 7.5 years of following-up the patients. The first TB case was reported on the $14^{\text {th }}$ day from ART initiation date. Table 1 contains the descriptive statistics of the study sample. Of the total of 357 HIV-infected patients enrolled in the study, 65 (18.2\%) were coinfected with TB and HIV. Out of the 65 HIV/AIDS patients with TB, 15 (23.1\%) of them died, thus of the 41 HIV/AIDS patients who died during the follow-up period, 15 of them (36.6\%) had TB as shown in Table 1.

Table 1: Frequency distribution of Patient status by TB history on last follow-up visit

\begin{tabular}{|c|c|c|c|c|}
\hline Frequency & & \multicolumn{3}{|c|}{ Patient status } \\
\hline$\%$ & TB historv & Alive & Died & Total \\
\hline \multirow{4}{*}{ Row \% } & \multirow{3}{*}{ Yes } & 50 & 15 & 65 \\
\cline { 1 - 3 } Column \% & 14.01 & 4.20 & 18.21 \\
\cline { 3 - 5 } & & 76.92 & 23.08 & \\
\cline { 3 - 5 } & & 15.82 & 36.59 & \\
\cline { 3 - 5 } & \multirow{4}{*}{ No } & 266 & 26 & 292 \\
\cline { 3 - 5 } & & 74.51 & 7.28 & 81.79 \\
\cline { 3 - 5 } & & 91.10 & 8.90 & \\
\cline { 3 - 5 } & Total & 84.18 & 63.41 & \\
\cline { 3 - 5 } & Percentage & 88.52 & 11.48 & 100.00 \\
\hline
\end{tabular}

\section{Fit statistics for data modelling using different regression models}

Table 2: Fit statistics for log-logistic, log-normal and exponential models

\begin{tabular}{|l|c|c|c|c|}
\hline & \multicolumn{3}{|c|}{ Regression models } & \\
\hline Fit statistics & Log-logistic & Log-normal & Exponential & Smallest \\
\hline -2 Log Likelihood & 843.766 & 864.882 & 15713.54 & Log-logistic \\
\hline AIC & 879.766 & 900.882 & 15747.54 & Log-logistic \\
\hline AICC & 881.790 & 902.906 & 15749.35 & Log-logistic \\
\hline BIC & 949.565 & 970.681 & 15813.46 & Log-logistic \\
\hline
\end{tabular}

From all the four fit statistics in Table 2, Log-logistics AFT model has the least fit statistics 
values, hence it was selected as the best model representing the research data shown in Table 3 in the following section.

\section{Determination of the factors associated with TB in HIV/AIDS patients}

\section{Fitting the Log-logistic AFT model}

Table 3 is a SAS output on the factors associated with TB in HIV-infected patients using loglogistic ATF model. The results obtained from AFT models unlike Cox model hazard ratio, are summarized in the exponentiated form as time ratio (TR) as shown in the last column of Table 1. Thus TR $>1$, indicates prolonged survival time, while TR $<1$ is associated with a decrease in survival time. Table 3 shows that the significant main effects at the 0.05 level of significance which are associated with better survival of HIV-infected patients from TB are Carolina hospital relative to Embhuleni hospital $(\mathrm{TR}=1.7580$, p-value $<0.0001)$ and follow-up CD4 count (TR=1.0006, p-value < 0.0001). A one unit increase in follow-up CD4 count makes a patient's average survival time from the onset of TB increase by about $0.06 \%$, after adjusting for other factors. The average TB-free survival time for Carolina hospital is about 1.76 times that of Embhuleni hospital, after adjusting for other factors. The average TB-free survival time for $(\mathrm{EFV}+\mathrm{D} 4 \mathrm{~T}+3 \mathrm{TC})$ is only 0.39 times that of $(\mathrm{NVP}+3 \mathrm{TC}+\mathrm{TDF})$ after adjusting for other factors. On the other hand, the following are the significant main effects at the 0.05 level of significance which are associated with poor survival of HIV-infected patients from TB: WHO stage 2 relative to $\mathrm{WHO}$ stage $4(\mathrm{TR}=0.6302$, p-value $<0.0069)$; WHO stage 3 relative to WHO stage $4(\mathrm{TR}=0.6517, \mathrm{p}$-value $<0.0021) ;(\mathrm{NVP}+\mathrm{D} 4 \mathrm{~T}+3 \mathrm{TC})$ relative to $(\mathrm{NVP}+3 \mathrm{TC}+\mathrm{TDF})$ $(\mathrm{TR}=0.2999, \mathrm{p}$-value $<0.0001) ;(\mathrm{EFV}+\mathrm{D} 4 \mathrm{~T}+3 \mathrm{TC})$ relative to $(\mathrm{NVP}+3 \mathrm{TC}+\mathrm{TDF})(\mathrm{TR}=0.3937$, p-value < 0.0001), $(\mathrm{EFV}+\mathrm{AZT}+3 \mathrm{TC})$ relative to $(\mathrm{NVP}+3 \mathrm{TC}+\mathrm{TDF}) \quad(\mathrm{TR}=0.4409, \mathrm{p}$-value < $0.0005) ;(\mathrm{EFV}+3 \mathrm{TC}+\mathrm{TDF})$ relative to $(\mathrm{NVP}+3 \mathrm{TC}+\mathrm{TDF}) \quad(\mathrm{TR}=0.6580, \mathrm{p}$-value < 0.0296); poor relative to good ART adherence $(\mathrm{TR}=0.3268$, p-value $<0.0001)$; fair relative to good ART adherence $(\mathrm{TR}=0.5718, \mathrm{p}$-value $<0.0001)$; baseline haemoglobin $(\mathrm{TR}=0.9356, \mathrm{p}$-value < 0.0005); follow-up white blood cell count $(\mathrm{TR}=0.9569$, $\mathrm{p}$-value $<0.0245)$; $\ln$ (baseline viral load) $(\mathrm{TR}=0.9388$, p-value $<0.0001)$; baseline sodium $(\mathrm{TR}=0.9804$, p-value $<0.0003)$ and follow-up Alanine Transaminase $(\mathrm{TR}=0.9939$, $\mathrm{p}$-value $<0.0007)$. A decrease in viral load is associated with an increase in survival probability from the onset of TB. Thus, a one unit decrease in $\ln$ (baseline viral load) makes a patient's average survival time from the hazard of TB decrease by about $6.1 \%$, after adjusting for other factors. 
Table 3: Results of fitting the Log-logistic AFT model

\begin{tabular}{|l|r|r|r|r|r|r|r|}
\hline \multicolumn{1}{|c|}{ Parameter } & Estimate & $\begin{array}{r}\text { Standard } \\
\text { Error }\end{array}$ & \multicolumn{2}{|c|}{$\begin{array}{r}\text { 95\% Confidence } \\
\text { Limits }\end{array}$} & $\begin{array}{r}\text { Chi- } \\
\text { Square }\end{array}$ & $\begin{array}{c}\text { Pr }> \\
\text { ChiSq }\end{array}$ & $\begin{array}{r}\text { Time } \\
\text { Ratio }\end{array}$ \\
\hline Intercept & 12.3744 & 0.9058 & 10.5990 & 14.1498 & 186.62 & $<.0001$ & 23664 \\
\hline $\begin{array}{l}\text { Hospital (Carolina vs } \\
\text { Embhuleni) }\end{array}$ & 0.5642 & 0.1121 & 0.3444 & 0.7840 & 25.31 & $<.0001$ & 1.7580 \\
\hline WHO Stage 1 vs 4 & 0.1754 & 0.2011 & -0.2187 & 0.5695 & 0.76 & 0.3831 & 1.1917 \\
\hline WHO Stage 2 vs 4 & -0.4617 & 0.1708 & -0.7965 & -0.1269 & 7.31 & 0.0069 & 0.6302 \\
\hline WHO Stage 3 vs vs 4 & -0.4281 & 0.1394 & -0.7012 & -0.1549 & 9.43 & 0.0021 & 0.6517 \\
\hline $\begin{array}{l}\text { Treatment(Regimen 1)=1 } \\
\text { (NVP+D4T+3TC) }\end{array}$ & -1.2043 & 0.1957 & -1.5879 & -0.8207 & 37.86 & $<.0001$ & 0.2999 \\
\hline $\begin{array}{l}\text { Treatment(Regimen 1)=5 } \\
\text { EFV+D4T+3TC) }\end{array}$ & -0.9321 & 0.1813 & -1.2874 & -0.5767 & 26.43 & $<.0001$ & 0.3937 \\
\hline $\begin{array}{l}\text { Treatment(Regimen 1)=6 } \\
\text { (EFV+AZT+3TC) }\end{array}$ & -0.8189 & 0.2342 & -1.2779 & -0.3599 & 12.23 & 0.0005 & 0.4409 \\
\hline $\begin{array}{l}\text { Treatment(Regimen 1)=18 } \\
\text { EFV+TDF+3TC) }\end{array}$ & -0.4185 & 0.1924 & -0.7955 & -0.0415 & 4.73 & 0.0296 & 0.6580 \\
\hline ART adherence=1 (Poor) & -1.1184 & 0.1556 & -1.4233 & -0.8135 & 51.68 & $<.0001$ & 0.3268 \\
\hline ART adherence=2 (Fair) & -0.5589 & 0.1255 & -0.8048 & -0.3130 & 19.84 & $<.0001$ & 0.5718 \\
\hline Follow-up CD4 & 0.0009 & 0.0002 & 0.0004 & 0.0013 & 14.94 & 0.0001 & 1.0006 \\
\hline Baseline haemoglobin & -0.0666 & 0.0192 & -0.1041 & -0.0290 & 12.05 & 0.0005 & 0.9356 \\
\hline $\begin{array}{l}\text { Follow-up white blood } \\
\text { cell count }\end{array}$ & -0.0441 & 0.0196 & -0.0825 & -0.0057 & 5.06 & 0.0245 & 0.9569 \\
\hline ln(Baseline viral load) & -0.0631 & 0.0108 & -0.0842 & -0.0420 & 34.23 & $<.0001$ & 0.9388 \\
\hline Baseline sodium & -0.0198 & 0.0055 & -0.0307 & -0.0090 & 12.84 & 0.0003 & 0.9804 \\
\hline $\begin{array}{l}\text { Follow-up Alanine } \\
\text { Transaminase }\end{array}$ & -0.0061 & 0.0018 & -0.0096 & -0.0026 & 11.53 & 0.0007 & 0.9939 \\
\hline Scale & 0.4364 & 0.0195 & 0.3998 & 0.4764 & & & \\
\hline
\end{tabular}

Key: Reference levels: (19=NVP+3TC+TDF) for treatment (regimen 1); 'Good' for ART adherence, 'Embhuleli' for hospital and WHO stage 4 for WHO stage. 


\section{Nonparametric inferences about the survivor functions on TB and HIV/AIDS}

The cohort of HIV/AIDS patients in this study is not homogeneous with respect to their characteristics that may affect their survival. Hence, it will be necessary to test the equality of survivor functions among groups (strata) of patients. Kaplan-Meier curves have become popular in medical research for reporting clinical results. However, comparison in terms of hazard rates is more informative than the survival curves. Consequently, hazard ratios for pairwise comparisons of strata are also presented. The interpretation of Kaplan-Meier survival functions for each main factor assumes that values of all other factors in the model are kept constant. Log-rank tests and the Kaplan-Meier functions presented in this section are for ART treatment (Regimen 1), ART adherence, hospital, viral load and CD4 count. These independent factors were found to be highly statistically significant in the log-logistic model (Table 1) and the difference their strata were also found to be highly significant (using log-rank test).

\section{Kaplan-Meier survival functions for Hospitals}

Figure 1 shows that throughout the follow-up period, HIV/AIDS patients from Embhuleni hospital have lower TB survival probability than patients from Carolina hospital.

Table 4: Hazard Ratios for Hospitals

Figure 1: Kaplan-Meier survival function estimates for Hospitals

\begin{tabular}{|l|c|c|c|}
\hline Description & $\begin{array}{c}\text { Point } \\
\text { Estimate }\end{array}$ & \multicolumn{2}{|c|}{$\begin{array}{c}95 \% \text { Wald } \\
\text { Confidence } \\
\text { Limits }\end{array}$} \\
\hline $\begin{array}{l}\text { Embhuleni } \\
\text { hospital relative } \\
\text { to Carolina } \\
\text { hospital }\end{array}$ & 14.15 & 3.455 & 57.95 \\
\hline
\end{tabular}

The hospital strata shown in the Figure 1 are statistically different as shown by both the logrank test $(\mathrm{p}$-value $=0.00)$ and the $95 \%$ Wald Confidence Limits for hazard ratios which do not include ' 1 ', a value of no effect. As shown in Table 4, HIV/AIDS patients at Carolina hospital relative to HIV/AIDS patients at Embhuleni hospital have lower hazard for TB. Furthermore, from Table 4, it can be concluded that an HIV/AIDS patient from Embhuleni hospital is about 14 times likely to experience TB relative to an HIV/AIDS patient from Carolina. 


\section{Kaplan-Meier survival functions for Treatments}

Figure 2 shows that throughout the follow-up period, HIV/AIDS patients taking $(\mathrm{NVP}+\mathrm{D} 4 \mathrm{~T}+3 \mathrm{TC})$ and those taking $(\mathrm{EFV}+3 \mathrm{TC}+\mathrm{TDF})$ experienced the least survival probability from TB while HIV/AIDS patients taking (NVP+3TC+TDF) experienced the highest survival probability from TB. The treatments shown in the Figure 2 are statistically different as shown by the log-rank test ( $\mathrm{p}$-value $=0.00$ ). As shown in Table 5, the ascending order of TB hazard in terms of each researched ART treatment relative to NVP+D4T+3TC is: $\mathrm{EFV}+\mathrm{AZT}+3 \mathrm{TC}, \mathrm{NVP}+3 \mathrm{TC}+\mathrm{TDF}$ and $\mathrm{EFV}+3 \mathrm{TC}+\mathrm{TDF}$. The ART treatment $\mathrm{EFV}+\mathrm{D} 4 \mathrm{~T}+3 \mathrm{TC}$ relative to NVP+D4T+3TC is not significant since the $95 \%$ confidence limits $(0.6539,2.0771)$ include ' 1 ', which is a value of no effect.

Table 5: Hazard Ratios for ART regimens

Figure 2: Kaplan-Meier survival function estimates for ART regimens

\begin{tabular}{|l|c|c|c|}
\hline Description & $\begin{array}{c}\text { Point } \\
\text { Estimate }\end{array}$ & \multicolumn{2}{|c|}{$\begin{array}{c}95 \% \text { Wald } \\
\text { Confidence } \\
\text { Limits }\end{array}$} \\
\hline $\begin{array}{l}\text { EFV+3TC+TDF } \\
\text { relative to } \\
\text { NVP+D4T+3TC }\end{array}$ & 0.0733 & 0.0159 & 0.3377 \\
\hline $\begin{array}{l}\text { EFV+D4T+3TC } \\
\text { relative to } \\
\text { NVP+D4T+3TC }\end{array}$ & 1.1637 & 0.6539 & 2.0710 \\
\hline $\begin{array}{l}\text { NVP+3TC+TDF } \\
\text { relative to } \\
\text { NVP+D4T+3TC }\end{array}$ & 0.18550 & 0.0418 & 0.8234 \\
\hline $\begin{array}{l}\text { EFV+AZT+3TC } \\
\text { relative to } \\
\text { NVP+D4T+3TC }\end{array}$ & 0.2508 & 0.0672 & 0.9351 \\
\hline
\end{tabular}

\section{Kaplan-Meier survival functions for ART adherence levels}

Figure 3 shows that throughout the follow-up period, HIV/AIDS patients with poor ART adherence have the least TB survival probability while patients with good ART adherence have the highest TB survival probability. The curves show substantial separation over time, showing that poor ART adherence is associated with increased TB hazard at long follow-up times. The three ART adherence levels shown in the Figure 3 are statistically different as shown by the log-rank test $(\mathrm{p}$-value $=0.00)$. 
Table 6: Hazard Ratios for ART adherence

Figure 3: Kaplan-Meier survival function estimates for ART adherence

\begin{tabular}{|l|c|c|c|}
\hline Description & $\begin{array}{c}\text { Point } \\
\text { Estimate }\end{array}$ & \multicolumn{2}{|c|}{$\begin{array}{c}\text { 95\% Wald } \\
\text { Confidence } \\
\text { Limits }\end{array}$} \\
\hline $\begin{array}{l}\text { Fair ART } \\
\text { adherence } \\
\text { relative to poor } \\
\text { ART adherence }\end{array}$ & 0.3632 & 0.2096 & 0.6294 \\
\hline $\begin{array}{l}\text { Good ART } \\
\text { adherence } \\
\text { relative to poor } \\
\text { ART adherence }\end{array}$ & 0.0978 & 0.0326 & 0.2931 \\
\hline
\end{tabular}

As shown in Table 6, patients with poor ART adherence relative to patients with good ART adherence are about 10 (1/0.0978) times likely to experience TB. On the other hand, patients with poor ART adherence relative to patients with fair ART adherence are about $3(1 / 0.3632)$ times likely to experience TB.

\section{Kaplan-Meier survival functions for Viral load groups}

Figure 4 shows that throughout the follow-up period, HIV/AIDS patients with baseline viral load above 50000 HIV RNA copies $/ \mathrm{mm}^{3}$ have the highest TB hazard, while HIV/AIDS

Figure 4: Kaplan-Meier survival function estimates for Viral load strata

Table 7: Hazard Ratios for Viral load strata

\begin{tabular}{|l|c|c|c|}
\hline Description & $\begin{array}{c}\text { Point } \\
\text { Estimate }\end{array}$ & \multicolumn{2}{|c|}{$\begin{array}{c}\text { 95\% Wald } \\
\text { Confidence Limits }\end{array}$} \\
\hline $\begin{array}{l}\text { Viral load from 50 } \\
\text { to 50 000 relative to } \\
\text { Viral load less than 50 }\end{array}$ & 1.216 & 0.2793 & 5.292 \\
\hline $\begin{array}{l}\text { Viral load above 50 } \\
\text { 000 relative to Viral } \\
\text { load less than 50 }\end{array}$ & 5.672 & 1.3710 & 23.465 \\
\hline
\end{tabular}

patients with non-detectable baseline viral load ( $<50$ HIV RNA copies $/ \mathrm{mm}^{3}$ ) have the least TB hazard. The three baseline viral load strata shown in the Figure 4 are statistically different as shown by the log-rank test ( $\mathrm{p}$-value $=0.00$ ). As shown in Table 7 , patients with baseline viral load above $50000 \mathrm{HIV}$ RNA copies $/ \mathrm{mm}^{3}$ relative to patients with baseline viral load less than 50 HIV RNA copies $/ \mathrm{mm}^{3}$ are about 6 times likely to experience TB. 


\section{Kaplan-Meier survival functions for Follow-up CD4 groups}

Figure 5 shows that throughout the follow-up period, AIDS patients with follow-up CD4 count $<200$ cells $/ \mathrm{mm}^{3}$ have higher TB hazard than HIV-infected patients with follow-up CD4 count $\leq 200$ cells $/ \mathrm{mm}^{3}$.

Table 8: Hazard Ratios for CD4 count strata

Figure 5: Kaplan-Meier survival function estimates for CD4 count strata

\begin{tabular}{|l|l|l|l|}
\hline Description & $\begin{array}{c}\text { Point } \\
\text { Estimate }\end{array}$ & \multicolumn{2}{|c|}{$\begin{array}{c}95 \% \text { Wald } \\
\text { Confidence } \\
\text { Limits }\end{array}$} \\
\hline $\begin{array}{l}\text { Follow-up CD4 count }< \\
200 \text { cells } / \mathrm{mm}^{3} \text { relative to } \\
\text { Follow-up CD4 count } \geq \\
200 \text { cells } / \mathrm{mm}^{3}\end{array}$ & 0.3171 & 0.1933 & 0.52 \\
\hline
\end{tabular}

The follow-up CD4 count strata in Figure 5 are statistically different as shown by the log-rank test $(\mathrm{p}$-value $=0.00)$. As shown in Table 8, AIDS patients with Follow-up CD4 count $<200$ cells $/ \mathrm{mm}^{3}$ relative to HIV-infected patients with Follow-up CD4 count $\geq 200$ cells $/ \mathrm{mm}^{3}$ are about 3 times likely to experience TB, and this effect can be as low as 2 times and as high as 5 times.

\section{Kaplan-Meier survival function for TB for Albert Luthuli HIVIAIDS data}

As shown in Figure 6, the estimate of the survival graph (bold) and its 95\% confidence intervals (dotted) graphs, the TB survival probability for the HIV/AIDS patients gradually declines over the follow-up period.

Table 9: TB survival probability of HIV/AIDS patients

Figure 6: Kaplan-Meier survival function estimate for TB in Albert Luthuli municipality (2010-2017)

\begin{tabular}{|l|c|c|l|}
\hline Description & $\begin{array}{c}\text { Point } \\
\text { Estimate }\end{array}$ & \multicolumn{2}{|c|}{$\begin{array}{c}95 \% \\
\text { Confidence } \\
\text { Intervals }\end{array}$} \\
\hline $\begin{array}{l}\text { TB survival } \\
\text { probability at the } \\
\text { end of follow-up } \\
\text { time (30-06-2017) }\end{array}$ & 0.647 & 0.535 & 0.783 \\
\hline
\end{tabular}

The decline in TB survival probability is associated to the factors in Table 3 . At the end of the follow-up time, the estimate of TB survival probability as in Figure 6 was at 0.647 and this estimate could go as low as 0.535 and as high as 0.783 . 


\section{Discussions}

To our knowledge, this is the first rural-based survival data study on Albert Luthuli municipality of South Africa to characterize in detail the epidemiological associations over time between the epidemics of TB and HIV infection. The impact of TB disease on survival in people living with HIV in low resource settings is not well documented in the antiretroviral treatment (ART) era. South Africa ranks among the worst afflicted countries in the world for both HIV infection and tuberculosis (TB). The researched prevalence of TB among HIV patients in Albert Luthuli municipality of South Africa was $18.2 \%$ and the HIV/AIDS deaths related to TB was $36.6 \%$. The proportion of TB/HIV co-infection reported in Ethiopia by Mekonnen et al. (2015) was $24.3 \%$, while the global AIDS deaths due to TB reported by WHO (2018) was around 33.3\%. The level of TB/HIV co-infection in Albert Luthuli municipality was more than twice the level of coinfection in England based on studies done by Zenner et al. (2015). The difference in prevalence findings could be explained by research design, populations studied, variables considered, and the criteria used for the diagnosis of TB. The proportion of TB/HIV co-infection was higher among females (60\%) and this is consistent with the findings by Ross et al. (2018) where the mortality among females was found to be above $75 \%$.

In consistent with the published literature by Ghate et al. (2011), in this study CD4 cell count and viral load have been found to be highly significant $(\mathrm{p}<0.0001)$ predictors of TB in HIV/AIDS patients. Studies have confirmed that sites of M. tuberculosis infection have increased viral replication in coinfected patients (Collins et al., $2002 \&$ Toossi et al., 2001). Pleural fluid from coinfected subjects has higher viral titers (Toossi et al. 2001) and greater HIV heterogeneity than plasma from the same patients (Collins et al. 2002). As shown in Figure 4, HIV/AIDS patients with detectable viral load (>50 000 HIV RNA copies $/ \mathrm{mm}^{3}$ ) have lower survival probability than HIV/AIDS patients with non-detectable viral load $(<50$ HIV RNA copies $/ \mathrm{mm}^{3}$ ). Many studies found out that people living with HIV and with a low CD4 count are much more susceptible to active TB. As shown in Figure 5 and Table 8, AIDS patients with follow-up CD4 count $\left(<200\right.$ cells $\left./ \mathrm{mm}^{3}\right)$ have lower TB survival probability than HIV/AIDS patients with follow-up CD4 count (>200 cells $/ \mathrm{mm}^{3}$ ). These findings emphasize the importance of creating awareness about early diagnosis for both TB and HIV. 
Antiretroviral therapy (ART) has proven to have a great impact on survival rates among HIVinfected patients with TB (Zhou et al., 2009; Masosuthi et al., 2006; Sungkanuparph et al., 2006). In follow-up studies of 1-2 years, Badri et al. (2002) and Lawn et al. (2005) found out that antiretroviral therapy reduces TB risk by 70\%-90\% in treated cohorts. In another study, Suchindran (2009) found out that the risk of death in co-infected individuals taking Antiretroviral therapy (ART) is twice that of HIV infected individuals without TB. In spite of ART having been shown to have a great impact on survival rates among HIV-infected patients with TB as in studies by Zhou et al. (2009), Manosuthi et al. (2006), Sungkanuparrph (2006) and by Zenner et al. (2015), this study has shown that there are some ART regimens which are positively associated with hazards among TB patients. As shown in Table 5, HIV/AIDS patients taking $\mathrm{NVP}+\mathrm{D} 4 \mathrm{~T}+3 \mathrm{TC}$ relative to $\mathrm{EFV}+3 \mathrm{TC}+\mathrm{TDF}$ are about 14 times likely to experience TB hazard. According to Teck et al. (2005) and Williams \& Dye (2003), there is concern that, although antiretroviral therapy is very effective in reducing an individual's risk of developing TB per unit time, the lifetime risk of the disease may not decrease. Thus, the overall burden of TB in the community may not substantially diminish, despite good antiretroviral coverage. Some other interventions that may also be important in reducing TB as suggested by Woldehanna and Volmink (2004) and Churchyard et al. (2003) include the use of primary and secondary isoniazid prophylaxis.

In addition to the predictors of TB, as shown in Table 3, ART adherence is a highly significant factor. Figure 3 and Table 6 show that HIV/AIDS patients with poor ART adherence relative to HIV/AIDS patients with good ART adherence are at higher risk to TB. Hospital is one of the factors associated with TB hazard. As shown in table 4, HIV/AIDS patients from Embhuleni hospital relative to HIV/AIDS patients from Carolina hospital are about 14 times likely to experience TB. The difference in TB hazard at the two hospitals could be attributed to the difference in management of TB. The ' $95 \%$ hazard ratio confidence limits for hospitals are extremely wide supposedly because of small sample size and heavy censoring (low TB rate and small sample size for Carolina hospital) (Fay et al, 2013).

This study shows that most TB cases from HIV-infected patients are from the first year $(44.6 \%)$ and second year $(36.9 \%)$ of following-up time of the HIV/AIDS patients. The high prevalence of TB in the first two years could mean that HIV/AIDS patients visit health centres for diagnosis of TB when their immunity systems are already weakened. This problem could be 
minimised by promoting earlier entry of HIV/AIDS patients into ART programmes especially in low-income countries (Lawn et al., 2011).

The TB test and the treatment of TB/HIV co-infection come with some challenges. The limitation of current TB tests is that it makes it more difficult to diagnose TB in HIV positive individuals than to diagnose TB in people without HIV infection. Patients with HIV may have a false negative result from a TB sputum smear test, and this can result in many cases of active TB disease going undiagnosed. Treating TB and HIV/AIDS at the same time can be challenging. The treatments for TB take a long time and can be difficult to take at the same time as ARVs. The additional challenge is that some TB drugs interact with ARVs, so treatment must be carefully planned if patient has both HIV and TB. Pigott (2011) indicated that the provision of HIV ARV therapy and anti TB drug treatment at the same time involves a number of potential challenges which include cumulative drug toxicities, drug - drug interactions and side effects, a high pill burden and the Immune Reconstitution Inflammatory Syndrome (IRIS).

WHO and UNAIDS intervene in TB/HIV co-epidemic by strongly advising countries to ensure that HIV programmes integrate regular TB screening, preventive therapy and early treatment. UNAIDS calls for the elimination of TB deaths among people living with HIV and for health systems to be strengthened and services integrated to allow for a more rapid scaleup of HIV and TB programming. Countries must expand HIV prevention and treatment programmes that include regular TB screening, preventive therapy and early treatment, since they are simple, affordable and effective programmes that prevent TB deaths. Despite TB-drug resistance and the ever increasing and aging HIV/AIDS community, the pursuance of the WHO policy on TB/HIV co-epidemic will yield favourable results in controlling of both HIV and Mycobacterium tuberculosis.

This research has several strengths. Firstly, research follow-up time of 7.5 years is relatively long to yield consistent records and hence reliable findings. Secondly, the research has diverse covariates with most of them having paired baseline and follow-up covariates for exhaustive comparisons of associations. Third, this was not a single-center study, it involved two district hospitals namely Embhuleni and Carolina for comparison and for completeness in coverage. Finally, there are several reasons why the AFT model is better suited to this study than the Cox proportional hazards model. Clinically, the AFT model analyses the time to event directly rather than hazard ratios, making the interpretation of the output clinically relevant and 
meaningful (Orbe et al., 2002). AFT model has also been found to perform better prediction than Cox model for the right-hand distribution of the model (Saberifiroozi et al., 2006), which was the main research interest in this study. Some studies showed that parametric models resulted in a better fit than the Cox's regression model (Nardi \& Schemper, 2003). When the proportionality assumption of Cox's regression model is not satisfied, the log-normal parametric model is the model of choice, moreover, simulation study showed that whether $\mathrm{PH}$ assumption is met or not, the log-logistic model is the best fitted model (Orbe et al., 2002).

Finally, this study has limitations. Some important factors like diabetes mellitus, Body Mass Index, education attained and hypertension that could potentially affect TB/HIV co-infection have not been considered. Considering the diversity of South Africa, our results from Albert Luthuli municipality need to be substantiated by similar survival studies from other parts of South Africa to give a comprehensive picture of TB/HIV co-infection in the entire country. Despite these limitations, our findings have policy implications and can be used as reference point in further studies.

\section{Conclusion}

In conclusion, the study presented the factors associated with TB among HIV/AIDS patients as: hospital, WHO stage, Treatment (regimen 1), ART adherence, follow-up CD4, baseline haemoglobin, follow-up white blood cell count, baseline viral load, baseline sodium and follow-up alanine transaminase. Thus, the study established diverse baseline statistics against which future research may be based. As the burden of HIV and TB co-infection in this study is relatively high, there is a need to increase funding to improve efforts for early detection and intervention for both HIV and TB. Understanding the key factors associated with TB in terms of death and non-death losses would assist in programmes evaluation and development. 


\section{Acknowledgement}

We are grateful to HIV/AIDS clinics staff for Carolina and Embhuleni hospitals. The Data capturers assisted with data collection while the administrative staff swiftly performed data collection permissions protocols.

\section{Author information}

\section{Author notes}

Pepukai Bengura, Prof Principal Ndlovu and Mulalo Annah Managa contributed equally to this work hence the corresponding author is transferable if the need arises.

\section{Authors' contributions}

PB was involved in obtaining ethics approval, data collection/analysis and drafting of the manuscript. PD and MAM contributed to data interpretation, project design and editing the manuscript. All authors read and approved the final manuscript.

\section{Corresponding author}

Correspondence to Pepukai Bengura.

\section{Funding}

Not applicable.

\section{Ethics declarations}

\section{Ethics approval and consent to participate}

This study was conducted in accordance with the South African local and national research guidelines. Ethics approval for this project was obtained from UNISA Ethics Review Committee (ERC) with the approval number being (2017/SSR ERC/005). The permission to conduct the study at Carolina and Embhuleni hospitals was obtained from Mpumalanga Department of Health with the permission number being (MP_201708_013). The consent to participate does not apply to a patient since no reference to an individual respondent was made, all results were handled in aggregate format.

\section{Availability of data and materials}

The data that support the findings of this study are available from the Department of health, but restrictions apply to the availability of these data, which were used under license for the current study, and so are not publicly available. Data are however available from the authors upon reasonable request and with permission of the Department of health.

\section{Consent for publication}

Not applicable. 


\section{Competing interests}

The authors declare that they have no competing interests.

\section{Author details}

${ }^{1}$ Department of Statistics, Unisa, Pretoria, South Africa

${ }^{2}$ Department of Statistics, Unisa, Pretoria, South Africa 


\section{References}

1. South Africa National AIDS Council. Let our actions count: South Africa's National Strategic Plan for HIV, TB and STIs 2017-2022. 2017. https://sanac.org.za/download-thefull-version-of-the-national-strategic-plan-for-hiv-tb-and-stis-2017-2022/. Accessed 10 Dec 2019.

2. World Health Organization. 'HIV-Associated Tuberculosis: factsheet', 2018.

Retrieved from: https://www.who.int/tb/areas-of-work/tb-hiv/tbhiv_factsheet.pdf?ua=1. Accessed 11 Dec 2019.

3. UNAIDS. 'Ending tuberculosis and AIDS: a joint response in the era of the Sustainable Development Goals - country submissions', 2018. Retrieved from: https://www.google.com/unaids+(2018)+ending+tuberculosis. Accessed 10 Dec 2019.

4. Getahun H, Gunneberg C, Granich R, Nunn P. HIV infection associated tuberculosis: the epidemiology and the response. Clin. Infect, 2010; 50 Suppl 3:S201-7. Retrieved from: doi: 10.1086/651492. Accessed 5 Nov 2019.

5. Karim SSA, Churchyard GJ, Karim QA \& Lawn SD. HIV infection and tuberculosis in South Africa: an urgent need to escalate the public health response. Lancet, 2009; 374(9693): 921-933. doi:10.1016/S0140-6736(09)60916-8. Accessed 16 Oct 2019.

6. Stop TB Partnership's Global Plan to End TB, World Health Organization, (Global Plan). Estimations on the annual global funding for TB in low- and middle-income countries. Geneva, Switzerland, 2017. Retrieved from: https://www.google.com/Stop TB Partnership's Global Plan to End TB. Accessed 23 Sept 2019.

7. Pawlowski A, Jansson M, Sko ld M, Rottenberg ME, Ka“llenius G. Tuberculosis and HIV Co-Infection. PLoS Pathog, 2012; 8(2): e1002464.

Retrieved from: doi:10.1371/journal.ppat.1002464. Accessed 28 Sept 2019

8. Zumla A, 2000, Postgrad Med J ,2000;76:259-268.

9. Bruchfeld J, Correia-Neves M \& Kallenius G, Cold Spring Harb Perspect Med, 2015; 5:a017871. Retrieved from: www.perspectivesinmedicine.org. Accessed 20 Nov 2019

10. Luetkemeyer A. "Tuberculosis and HIV", HIVInSite, 2019. Retrieved from: http://hivinsite.ucsf.edu/. Accessed 14 Dec 2019

11. Glynn JR, Murray J, Bester A, Nelson G, Shearer S, Sonnenberg P. Effects of duration of HIV infection and secondary tuberculosis transmission on tuberculosis incidence in the 
South African gold mines. AIDS, 2008; 22(14):1859-67. Retrieved from: doi: 10.1097/QAD.0b013e3283097cfa. Accessed 2 Oct 2019.

12. Mekonnen D, Awoke Derbie A \& Desalegn E. TB/HIV co-infections and associated factors among patients on directly observed treatment short course in Northeastern Ethiopia: a 4 years retrospective study. BMC Res Notes, 2015; 8:666 DOI 10.1186/s13104-015-1664-0. Accessed 20 Oct 2019

13. Masini E, Mansour O, Speer CE, Addona V, Hanson CL, Sitienei JK, Kipruto HK, Githiomi MM \& Mungai BN. Using Survival Analysis to Identify Risk Factors for Treatment Interruption among New and Retreatment Tuberculosis Patients in Kenya. Plos one, 2016; 11(10):e0164172. DOI: 10.1371/journal.pone.0164172. Accessed 23 Sept 2019

14. Eneyew K, Seifu D, Amogne W, Menon M. Assessment of Renal Function among HIV Infected Patients on Combination Antiretroviral Therapy at Tikur Anbessa Specialized Hospital ,Addis Ababa ,Ethiopia. Sci Res Pub, 2016;7(August):107-22. DOI:10.4236/ti.2016.73013. Accessed 12 Feb 2018.

15. Manosuthi W, Chottanapand S, Thongyen S, Chaovavanich A, Sungkanuparph S. Survival rate and risk factors of mortality among HIV/tuberculosis-coinfected patients with and without antiretroviral therapy. J Acquir Immune Defic Syndr, 2006;43:42-6. Accessed 21 Sept 2019

16. Schwarz, G.E. Estimating the dimension of a model. Ann. Stat, 1978; 6: 461-464. DOI: 10.1214/aos/1176344136. Accessed 4 Nov 2019

17. Kim DK. Regression Analysis of Interval-Censored Survival Data with Covariates Using Log-Linear Models. International Biometric Society, 1997;

Vol. 53, No. 4 pp. 1274-1283. Retrieved from: https://www.jstor.org/stable/2533496. Accessed 12 Nov 2019.

18. Swain, PK \& Grover G. Determination of Predictors associated with HIV/AIDS patients on ART using accelerated failure time model for interval censored survival data. Department of Statistics, Faculty of Mathematical Sciences, University of Delhi, India, 2016.

19. Collett, D. Modelling Survival Data in Medical Research. 1st Edn., CRC Press, London, 2003; ISBN-10: 1584883251, pp: 410.

20. Klein JP \& Moeschberger ML. Survival analysis Techniques for Censored and Truncated Data. Ohio. USA. Springer, 2003.

21. Zenner D, Abubakar I, Conti S, Gupta RK, Yin Z, Kall M, Kruijshaar M, Rice B, Thomas HL, Pozniak A, Lipman M, Delpech V. Impact of TB on the survival of people living with HIV infection in England, Wales and Northern Ireland. Thorax, 2015; 70:566-573. Retrieved from: doi:10.1136/thoraxjnl-2014-206452. Accessed 18 Sept 2019 
22. Ross JM, Henry NJ, Dwyer-Lindgren LA, de Paula Lobo A, de Souza FM, Biehl MH,...Hay SI. Progress toward eliminating TB and HIV deaths in Brazil, 2001-2015: a spatial assessment. BMC Medicine, 2018; 16:144. Retrieved from: https://doi.org/10.1186/s12916-018-1131-6. Accessed 13 Nov 2019

23. Ghate M, Tripathy S, Gangakhedkar R, Thakar M, Bhattacharya J, Choudhury I.,... Ramesh Paranjape. Effects of antiretroviral therapy in HIV infected individuals in Pune. Indian J Med Res, 2013; 137, pp 942-949. Accessed 15 Oct 2019

24. Collins KR, Quiñones-Mateu ME, Wu M, Luzze H, Johnson JL, Hirsch C, Toossi Z and Arts EJ. Collins KR., et al. Human immunodeficiency virus type 1 (HIV-1) quasispecies at the sites of Mycobacterium tuberculosis infection contribute to systemic HIV-1 heterogeneity. J, 2002; Virol.76:1697-1706. Accessed 30 Sept 2019.

25. Toossi Z, Johnson JL, Kanost RA, Wu M, Luzze H, Peters P.,...Hirsch CS. Increased replication of HIV-1 at sites of Mycobacterium tuberculosis infection: potential mechanisms of viral activation. J.Acquir. Immune Defic. Syndr, 2001; 28:1-8. Accessed 12 Aug 2019.

26. Zhou J, Elliott J, Li PC, Lim PL, Kiertiburanakul S, Kumarasamy N.,....Ditangco R. Risk and prognostic significance of tuberculosis in patients from The TREAT Asia HIV observational Database. BMC Infect Dis, 2009; 9:46. Accessed 28 Aug 2019.

27. Sungkanuparph S, Manosuthi W, Kiertiburanakul S, Vibhagool A. Initiation of antiretroviral therapy in advanced AIDS with active tuberculosis: clinical experiences from Thailand. J Infect, 2006; 52:188-94. Accessed 21 Aug 2019.

28. Badri M, Wilson D, Wood R. Effect of highly active antiretroviral therapy on incidence Of tuberculosis in South Africa: a cohort study. Lancet, 2002; 359:2059-64. Accessed 28 Oct 2019.

29. Lawn SD, Bekker LG, Wood R. How effectively does HAART restore immune responses to Mycobacterium tuberculosis? Implications for tuberculosis control. AIDS, 2005a; 19:1113-24. doi: 10.1097/01.aids.0000176211.08581.5a. Accessed 25 Sept 2019.

30. Lawn SD, M. Török ME, Wood R. Optimum time to start antiretroviral therapy during HIV-associated opportunistic infections. Curr Opin Infect Dis, 2011; 24(1): 34-42. doi:10.1097/QCO.0b013e3283420f76. Accessed 22 Aug 2019.

31. Suchindran S. "Is HIV infection a Risk Factor for Multi-Drug Resistant Tuberculosis? A Systematic Review" PLoS one, 2009; 4(5): e5561. Retrieved from: http://www.plosone.org/article/. Accessed 30 Sept 2019.

32. Teck R, Ascurra O, Gomani P, et al. WHO clinical staging of HIV infection and disease, tuberculosis and eligibility for antiretroviral treatment: relationship to CD4 lymphocyte counts. Int J Tuberc Lung Dis, 2005; 9:258-62. Accessed 22 Nov 2019. 
33. Williams BG, Dye C. Antiretroviral drugs for tuberculosis control in the era of HIV/AIDS. Science, 2003; 301:1535-7. Accessed 20 Nov 2019.

34. Churchyard GJ, Fielding K, Charalambous S, et al. Efficacy of secondary isoniazid preventive therapy among HIV-infected Southern Africans: time to change policy? AIDS 2003; 17:2063-70. Accessed 12 Nov 2019.

35. Woldehanna S, Volmink J. Treatment of latent tuberculosis infection in HIV infected persons. Cochrane Database Syst Rev, 2004; CD000171. Accessed 21 Oct 2019.

36. Fay MP, Brittain EH, \& Proschan MA. Pointwise confidence intervals for a survival distribution with small samples or heavy censoring. Biostatistics, 2013; 14 (4)723-736. doi:10.1093/biostatistics/kxt016. Accessed 19 Jun 2020.

37. Piggott D. "Timing of Antiretroviral Therapy for HIV in the Setting of TB Treatment" Clin Dev Immunol, 2011; 103917. Retrieved from: www.hindawi.com/journals/cdi/" Accessed 6 Oct 2019.

38. Orbe J, Ferreira E, Nunez-Anton V. Comparing proportional hazards and accelerated failure time models for survival analysis. Stat Med, 2002; 21:3493-510. Accessed 13 Nov 2019.

39. Saberifiroozi M, Serati AR, Malekhosseini SA, et al. Analysis of patients listed for liver transplantation in Shiraz, Iran. Ind J Gastroenterol, 2006; 25:11-3. Accessed 16 Aug 2019.

40. Nardi A, Schemper M. Comparing Cox and parametric models in clinical studies. Stat Med, 2003; 22:3597-610. Accessed 20 Nov 2019. 


\section{Figures}

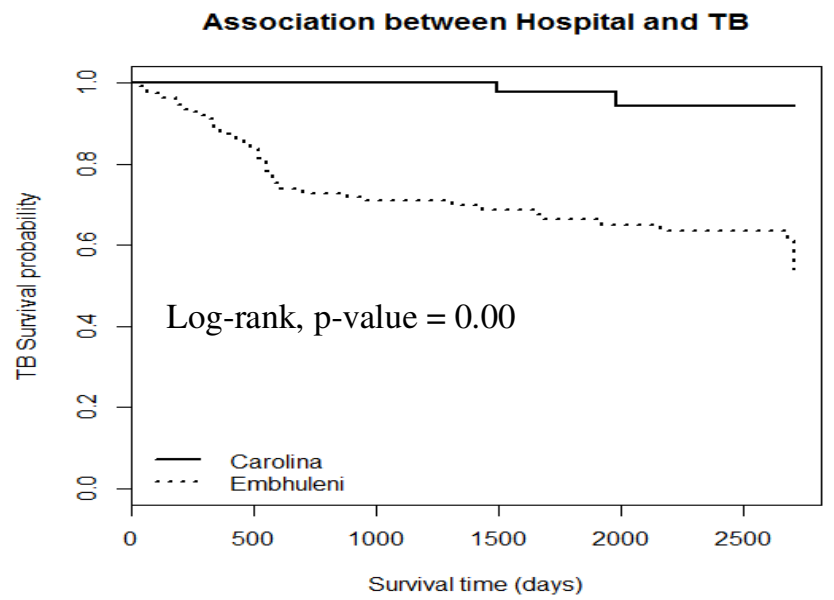

Figure 1: Kaplan-Meier survival function estimates for Hospitals

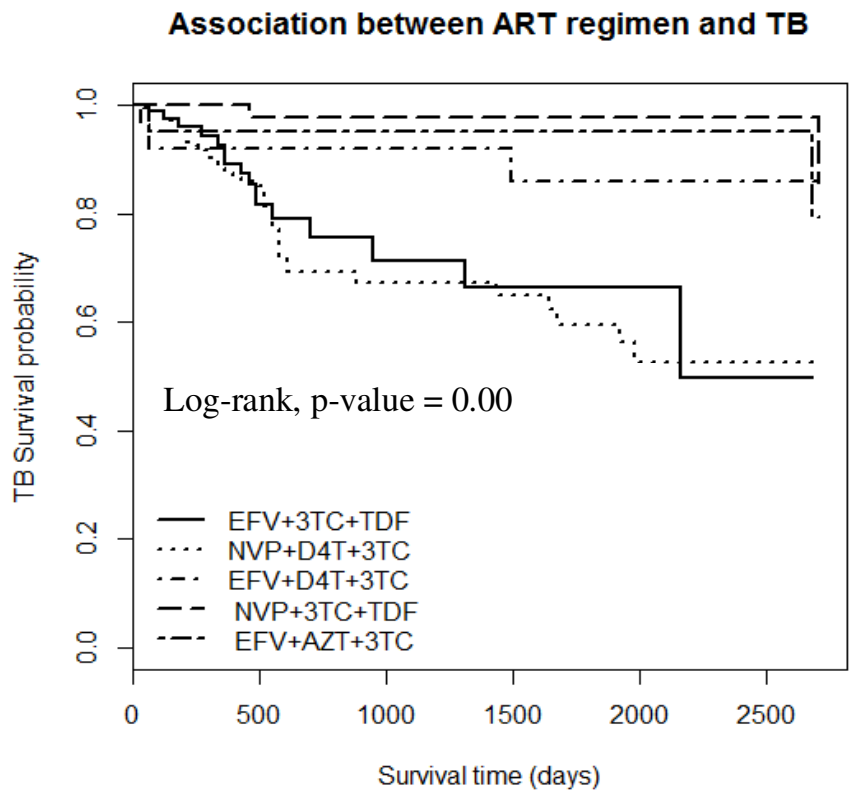

Figure 2: Kaplan-Meier survival function estimates for ART regimens 


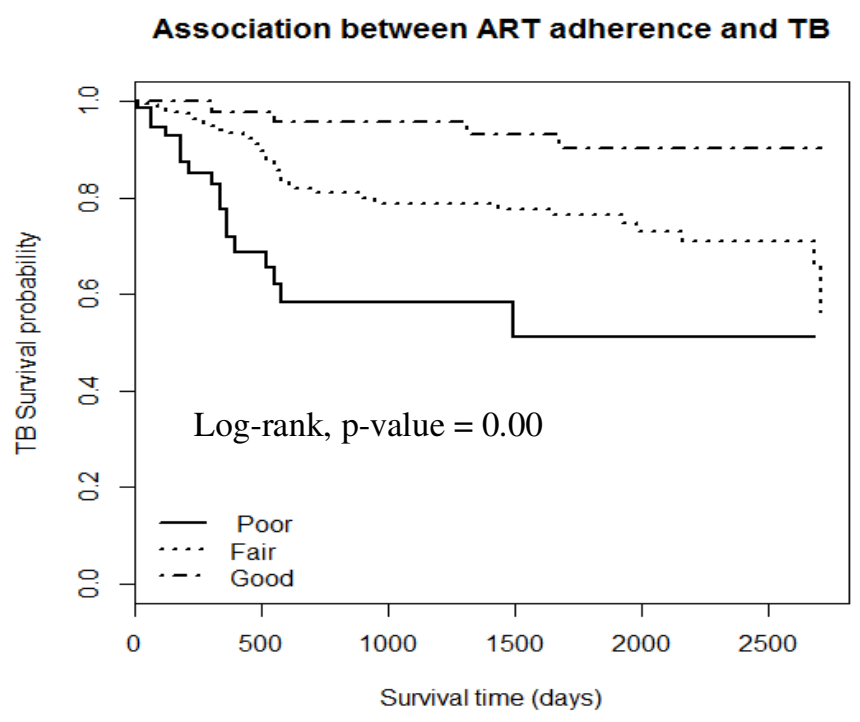

Figure 3: Kaplan-Meier survival function estimates for ART adherence

Association between Baseline viral load and TB

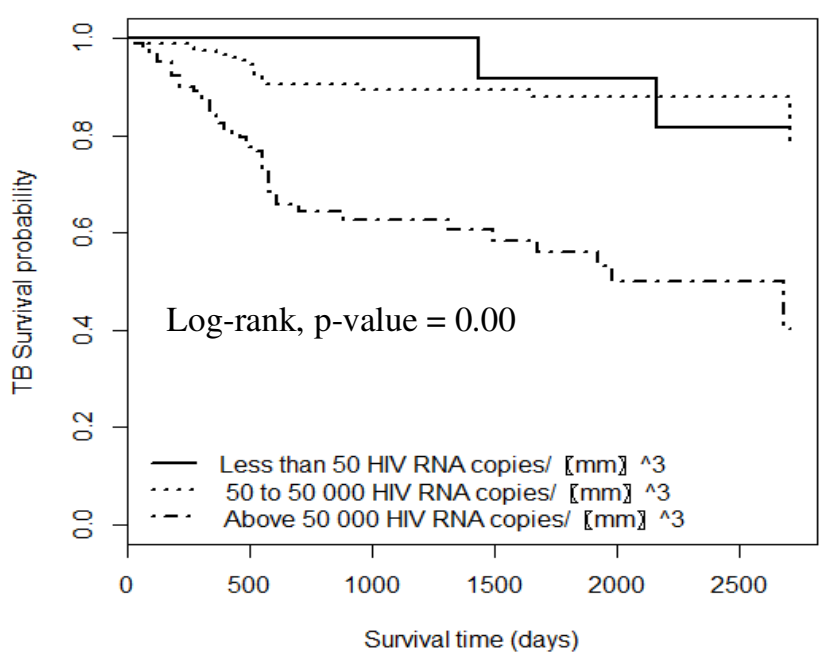

Figure 4: Kaplan-Meier survival function estimates for Viral load strata 


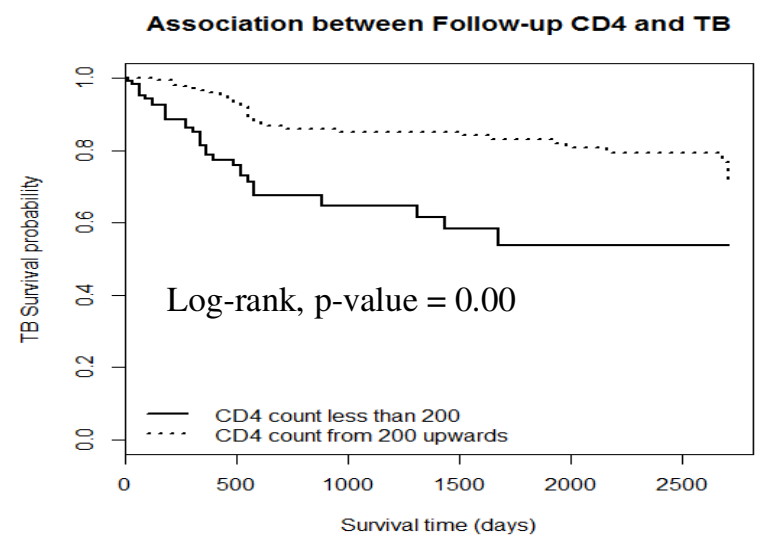

Figure 5: Kaplan-Meier survival function estimates for $\mathrm{CD} 4$ count strata

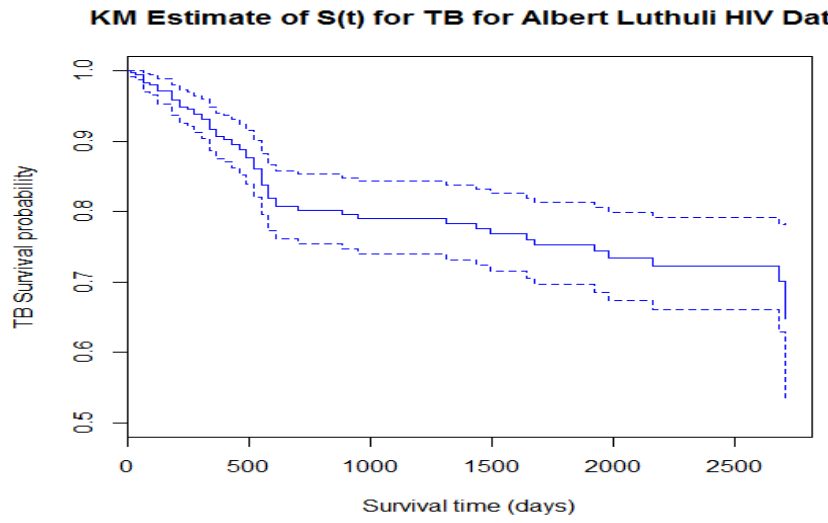

Figure 6: Kaplan-Meier survival function estimate for TB in Albert Luthuli municipality (2010-2017) 
Figures

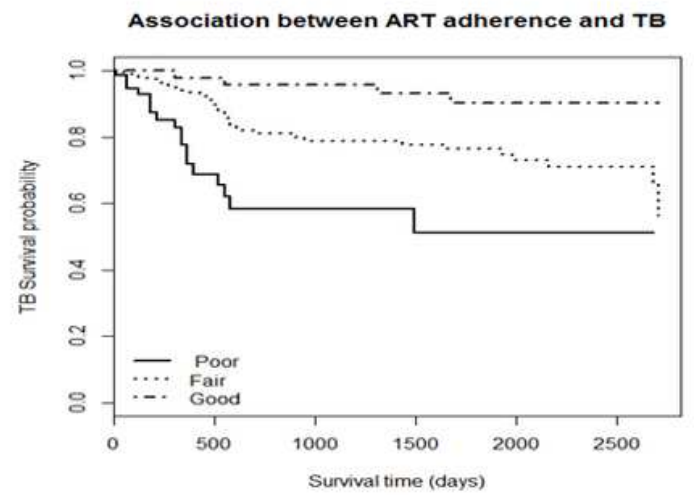

Figure 1

Kaplan-Meier survival function estimates for Hospitals

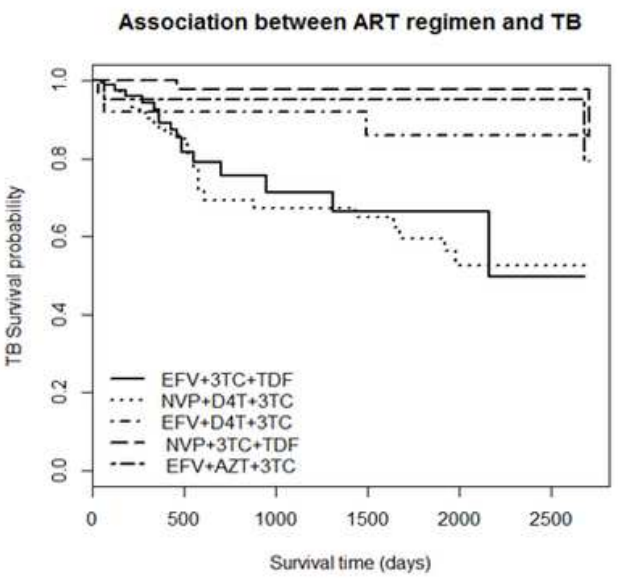

Figure 2

Kaplan-Meier survival function estimates for ART regimens 


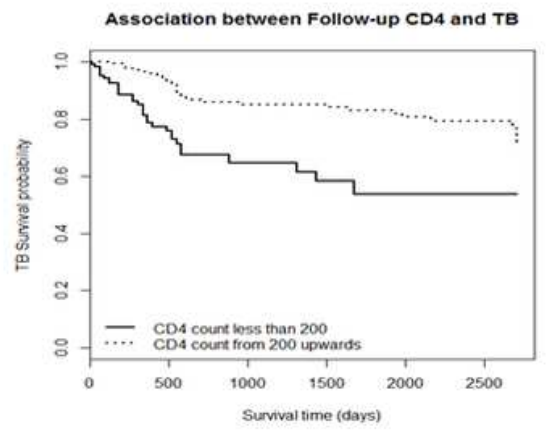

\section{Figure 3}

Kaplan-Meier survival function estimates for ART adherence

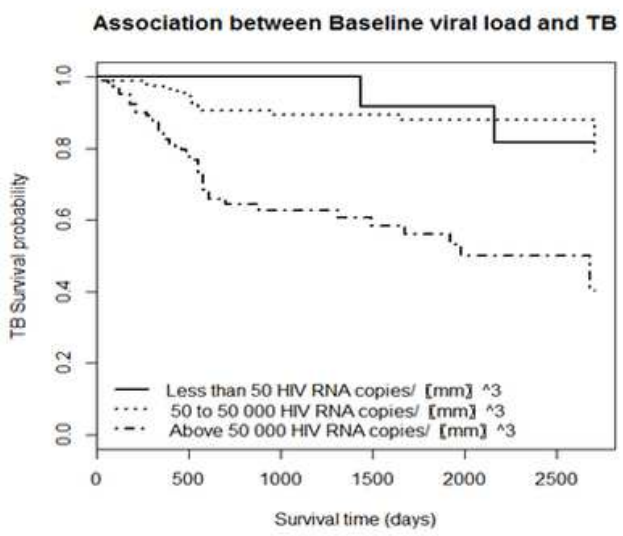

Figure 4

Kaplan-Meier survival function estimate for TB in Albert Luthuli municipality (2010-2017) 